Scoring System for Sleep Stages of Human Subjects. Washington, DC: National Institute of Health Publication no. 204, US Government Printing Office.

Rush AJ, Giles DE, Roffwarg HP, Parker CR Jr (1982): Sleep EEG and Dexamethasone Suppression Test findings in outpatients with unipolar major depressive disorder. Biol Psychiatry 17:327-341.

Rush AJ, Erman MK, Giles DE, Schlesser MA, Carpenter G, Vasavada N, Roffwarg HP (1986): Polysomnographic findings in recently drug-free and clinically remitted depressed patients. Arch Gen Psychiatry 43:878-884.

Spitzer RL, Endicott J, Robins E (1978): Research Diagnostic Criteria: Rationale and reliability. Arch Gen Psychiatry 36:773-782.

Tsuang MT, Winokur G, Crowe R (1980): Morbidity risks of schizophrenia and affective disorders among first-degree relatives of patients with schizophrenia, mania, depression and surgical conditions. Br J Psychiatry 137:497-504.

Webb W, Campbell SS (1983): Relationships in sleep characteristics of identical and fratemal twins. Arch Gen Psychiatry 40:1093-1095.

Weissman MM, Gershon ES, Kidd KK, Prusoff BA, Leckman JF, Dibble E, Hamovit J, Thompson D, Pauls DL, Guroff JJ (1984): Psychiatric disorders in the relatives of probands with affective disorders. The Yale University-National Institute of Mental Health Collaborative Study. Arch Gen Psychiatry 41:13-21.

Winokur G, Cadoret R, Dorzab J, Barker M (1971): Depressive disease: A genetic study. Arch Gen Psychiatry 24:135-144.

\title{
Chronic Inescapable Footshock Produces Cholinergic System Supersensitivity
}

\section{Steven C. Dilsaver and Norman E. Alessi}

\section{Introduction}

Dilsaver et al. (1986) reported that chronic swim stress produced cholinergic system supersensitivity in rats. However, an attribute peculiar to chronic swim stress could account for the enhanced sensitivity to the hypothermic effects of oxotremorine (OXO) that we observed follow-

From the Department of Psychiatry, Mental Health Research Institute, University of Michigan. Ann Arbor, MI.

Supported in part by Physician-Scientist Career Development Award (Muscarinic Receptor Abnormalities in Affective Illness) Grant 5RC 1K11 MH0055031.

Address reprint requests to Dr. S.C. Dilsaver, Department of Psychiatry, Mental Health Research Institute, 205 Washtenaw Place, Ann Arbor, MI 48109-1687.

Received August 30. 1986; revised December 4, 1986. ing forced swim stress. Thus, we measured the effects of chronic inescapable footshock on the sensitivity of adult rats to the hypothermic effects of OXO.

\section{Methods}

\section{Temperature Measurement}

Telemetric thermosensors (Mini-Mitter Co., Sun River, OR) were implanted into the peritoneal cavity. These devices emit Hertzian waves at a rate proportional to temperature. A transistor radio set to an AM frequency served as a receiver. Time to emit 10 sounds was measured using a digital display stopwatch. This measure 
was converted to temperature using a linear regression equation that was derived by measuring the emission rate of the thermosensors at three temperatures in a temperature-controlled water bath. The instrument allows the accurate detection of a change in temperature of $0.1^{\circ} \mathrm{C}$ (Tocco-Bradley et al. 1985).

\section{Oxotremorine Challenge}

OXO challenges were conducted between 11:00 $\mathrm{AM}$ and 1:00 PM and were preceded by the administration of methylscopalmine nitrate, 1 $\mathrm{mg} / \mathrm{kg}$ ip, to block the peripheral effects of the muscarinic agonist. Baseline temperature was measured $30 \mathrm{~min}$ later. OXO (base), $1 \mathrm{mg} / \mathrm{kg}$ ip, was then given, and temperature was recorded every $10 \mathrm{~min}$ for $120 \mathrm{~min}$.

\section{Inescapable Footshock}

Inescapable footshock started 5 days after the implantation of thermosensors. The animals were stressed between 10:00 AM and 2:00 PM. The procedure involved placing the animals in a plexiglass chamber with a metal floor. Two milliamps of current passed through the grid for a continuous second every $5 \mathrm{sec}$. Stress sessions lasted $30 \mathrm{~min}$. Afterwards, the animals were removed and returned to their cages.

\section{Experimental Design}

The study involved three phases.

Phase I (Implantation). Thirteen male Sprague-Dawley rats $(263.3 \pm 22.1 \mathrm{~g})$ participated in Phases I and II. The first OXO challenge marked the end of Phase I and provided a baseline against which data from subsequent challenges could be evaluated. Animals participating in Phases I and II came from two cohorts, only one of which contained animals that were carried beyond to Phases III and IV.

Phase II (Inescapable Footshock). This phase started with the first of five sessions of inescapable footshock and ended with the second OXO challenge, which followed the fifth footshock session by about $24 \mathrm{hr}$.

Phase III (Continued Footshock). During this phase, seven animals continued to receive four additional sessions of footshock. This phase ended $24 \mathrm{hr}$ after the ninth session of footshock, when the animals were given their third OXO challenge. There were no differences in the weights of animals receiving $5(280.7 \pm 13.8 \mathrm{~g})$ or 9 days $(283.0 \pm 14.3 \mathrm{~g})$ of inescapable footshock.

Phase IV (Rest). During this phase, the animals were not stressed. The phase terminated with the last (i.e., fourth) OXO challenge.

\section{Statistical Analysis}

Magnitude of the change in body temperature at each time point $(10,20 \ldots 120 \mathrm{~min}$ after the injection of OXO) and the mean and maximum thermic response before relative to after 5 or 9 days of stress or 14 days of rest were designated as dependent variables. The level of significance of the difference in the mean thermic response at the 12 time points was determined by calculating the apposite confidence intervals. The paired Student's $t$-test was used to assess the level of significance in the difference between within-animal measurements of thermic responsiveness after 5 or 9 stress sessions and 14 days of rest relative to baseline.

\section{Results}

Nine of 13 animals exhibited a significant increase in the mean hypothermic response after 5 days of inescapable footshock. Furthermore, the mean hypothermic response of this sample, relative to baseline, also increased significantly (mean $\pm \mathrm{SEM}, \quad 0.54 \pm 0.19^{\circ} \mathrm{C}, \quad p<0.01$, $t=3.71,12 \mathrm{df}$, paired $t$-test). Seven animals received 9 continuous days of inescapable footshock. Six of these showed a significant increase in the mean hypothermic response, and the sample also exhibited a significant increase in the 


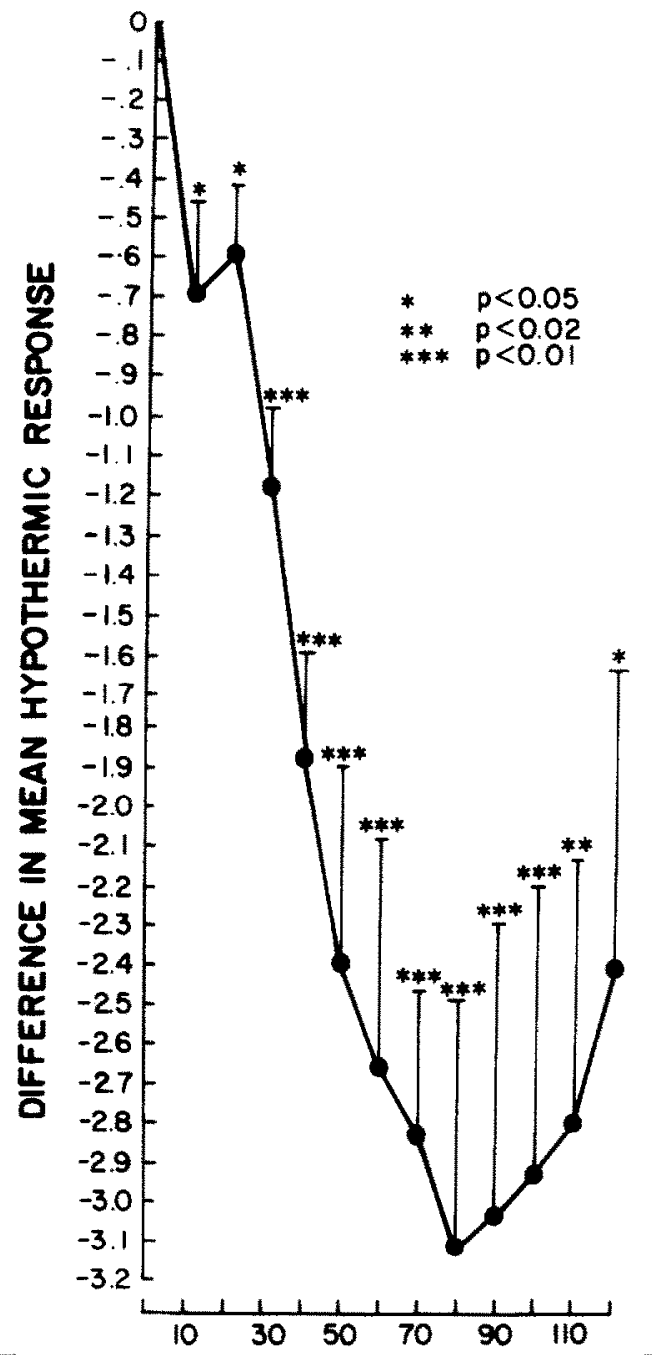

TIME FROM THE INJECTION OF OXOTREMORINE

Figure 1. This illustrates the difference in the mean hypothermic response at each of 12 points in time $(10,20,30 \ldots 120 \mathrm{~min})$ after the injection of oxotremorine before (i.e., at the prestress baseline) and after 9 sessions of daily inescapable footshock in a sample of 7 rats. The hypothermic response at any given point in time for an individual animal equals the absolute value of the core temperature at that point in time minus the absolute value of the core temperature 30 min after the injection of methylscopolamine nitrate. There was an increase in the hypothermic response at all 12 points $(p=0.0002)$. The probability statements are based on nonoverlap of the $95 \%$ or narrower confidence interval with " 0 ."

mean hypothermic response $\left(2.38 \pm 0.67^{\circ} \mathrm{C}\right.$, $p<0.01, t=3.78,6 \mathrm{df}$, paired $t$-test).

Five animals were studied over a 4-week period, which included 14 consecutive days during which they were not stressed. Three of these animals demonstrated a significant increase in the hypothermic response relative to the prestress baseline, and a fourth exhibited a trend toward enhanced sensitivity to OXO. After 14 days of "rest," the mean hypothermic response 
remained elevated $\left(0.87 \pm 0.17^{\circ} \mathrm{C}, t=5.12\right.$, $5 \mathrm{df}, p<0.01$, paired $t$-test). Figure 1 summarizes the data.

After 5 and 9 days of inescapable footshock, the samples also demonstrated enhancement of the hypothermic response at each of the 12 time points ( $p=0.0002$, sign test). The sample receiving 9 days of footshock demonstrated a significant increase in the response at 6 of these points. Animals receiving 9 days of treatment also demonstrated enhancement of the hypothermic response at each of the 12 time points at which temperature was measured relative to their response after the fifth session $(p=0.0002$, sign test).

Prolonged exposure to inescapable footshock seemed to confer increased sensitivity to OXO. The difference in the hypothermic response of cach animal after 9 days of footshock relative to 5 provided an index of change in its sensitivity to $0 X 0$. The 7 animals receiving 9 consecutive days of inescapable footshock demonstrated an enhancement of the mean hypothermic response relative to their response after the fifth session of $1.96 \pm 0.48(t=4.08,6 \mathrm{df}, p<0.01$, paired $t$-test).

\section{Discussion}

We previously reported that chronic swim stress enhanced the hypothermic response to OXO (Dilsaver et al., 1986). These results indicate that chronic inescapable footshock also produces supersensitivity of a central muscarinic mechanism and provides prima facie validation of the hypothesis that chronic stress activates cholinergic mechanisms.

The literature emphasizes the impact of stress on monoaminergic systems (Weiss et al. 1981). However, Gilad et al. (1985) reported that the septo-hippocampal cholinergic system in rats undergoes rapid activation during acute stress. This is expressed by an increase in high-affinity uptake of choline and the release of acetylcholine (Ach). Estevez et al. (1981) reported that forced swimming resulted in an acute $(27 \%)$ decrease in the density of tritiated quinuclidinyl benzilate binding $\left(\left[{ }^{3} \mathrm{H}\right] \mathrm{QNB}\right)$ sites in the cere- bral cortex and basal ganglia. This change persisted for $60 \mathrm{~min}$ in the cortex and $24 \mathrm{hr}$ in the basal ganglia. This is compatible with the idea that acute and chronic stress mobilize cholinergic mechanisms. The reduction in the density of QNB binding sites could be due to increased release of Ach. The density of muscarinic receptors (mAchRs) is subject to the availability of endogenous or exogenous agonists (Gazit et al. 1974; Siman and Klein 1979; Ehlert et al. 1980; Shifrin and Klein, 1980). It is also possible that the reduction in binding sites could be due to a decreased density of presynaptic mAchRs. This could increase the release of Ach. Regardless, it is essential to note that these data pertain to animals subject to acute stress. Chronic stress could produce different findings. However, both bodies of information might be consistent with the concept that stress activates cholinergic pathways. For instance, in the acute paradigm, stress may produce an increased release of Ach. Increased release of Ach could in turn produce an agonist dependent down-regulation of postsynaptic mAchRs. In contrast, chronic stress could supersensitize muscarinic systems by affecting up-regulation of mAchRs.

The significance of these findings may partially lie in the capacity of cholinergic mechanisms to mediate effects of stress in affective disorder patients. Cholinergic system dysfunction may be involved in the pathophysiology of affective disorders (Janowsky et al. 1972; Dilsaver 1986a,b). Epidemological data indicating associations between stressful events and the onset of depressive (Lloyd 1980) and manic (Kennedy et al. 1983) episodes suggest that an animal model useful in studying the effects of stress on cholinergic parameters in vivo would be of theoretical importance. Investigators recently proposed that stress increases the sensitivity of central cholinergic mechanisms in humans and that this mediates some of its neurobiological effects (Janowsky et al. 1983, 1985; Dilsaver 1986a). However, until now, animal models linking the pathophysiologies of depression, mania, stress, and cholinergic systems have neither been available nor the subject of serious study. Animal models linking stress 
and sensitivity of cholinergic systems promises to bridge the neurobiologies of anxiety, affective disorders (Janowsky et al. 1972; Dilsaver 1986b-e), and cholinergic mechanisms.

\section{References}

Dilsaver SC (1986a): Cholinergic-monoamine systems, depression, and panic. Biol Psychiatry 21:571-573.

Dilsaver SC (1986b): Pathophysiology of "cholinoceptor supersensitivity" in affective disorders. Biol Psychiatry 21:813-829.

Dilsaver SC (1986c): Pharmacologic induction of cholinergic system up-regulation and supersensitivity in affective disorders research. J Clin Psychopharmacol 6:65-74.

Dilsaver SC (1986d): Cholinergic hypothesis of depression. Brain Res Rev 11:285-316.

Dilsaver SC (1986e): Cholinergic mechanisms in affective disorders: Future directions. Acta Psychiatr Scand 74:312-334.

Dilsaver SC, Snider RM, Alessi NE (1986): Stress induces supersensitivity of a cholinergic system in rats. Biol Psychiatry 21:1093-1096.

Ehlert FJ, Kukka N, Fairhurst AS (1980): Altered $\left[{ }^{3} \mathrm{H}\right]$ quinuclidinyl benzilate binding in the striatum of rats following chronic cholinesterase inhibition with diisopropylflurophosphonate. Mol Pharmacol 17:29-30.

Estevaz EE, Jervsalinski S, Medina JH, et al (1981): Cholinergic muscarinic receptors in rat cerebral cortex, basal ganglia and cerebellum undergo rapid and reversible changes after acute stress. Neuroscience 13:1353-1357.

Gazit H, Silaman I, Dudai Y (1974): Administration of an oranophosphate causes a decrease in muscarinic receptor levels in rat brain. Brain Res 174:354-356.
Gilad GM, Mahon BD, Finkelstein Y, et al (1985): Stress-induced activation of the hippocampal cholinergic system and the pituitary adrenal axis. Brain Res 347:404-408.

Janowsky DS, El-Yousef MK, Davids JM, et al (1972): A cholinergic adrenergic hypothesis of mania and depression. Lancet ii:632-635.

Janowsky DS, Risch SC, Huey L. Judd L, Rousch J (1983): Central physostigmine-induced cardiovascular and behavioral changes: Toward an acetylcholine hypothesis of stress. Psychopharmacol Bull 19:675-682.

Janowsky DS, Risch SC, Huey L, et al (1985): Effects of physostigmine in pulse, blood pressure and serum epinephrine levels. Am J Psychiatr 142:738-740.

Kennedy S, Thompson R, Stancer HC, Roy A, Persad E (1983): Life events precipitating mania. $B r$ $J$ Psychiatry 142:398-403.

Lloyd C (1980): Life events and depressive disorder: II. Events as precipitating factors. Arch Gen Psychiatry 37:541-548.

Shifrin GS, Klein WL (1980): Regulation of muscarinic acetylcholine receptor concentration in cloned neuroblastoma cells. J Neurochem 34:993-999.

Siman RG, Klein WL (1979): Cholinergic activity regulates muscarinic receptors in central nervous system cultures. Proc Natl Acad Sci USA 76:4141-4145.

Tocco-Bradley R, Kluger MJ, Kauffman CA (1985): Fffect of age on fever and acute-phase response of rats to endotoxin and Salmonella typhimurium. Infect Immun 47:106-111.

Weiss JM, Goodman PA, Losito BG, Corrigan S, Charry JM, Bailey WH (1981): Behavioral depression produced by an uncontrollable stressor: Relationship to norepinephrine, dopamine and serotonin levels in various regions of rat brain. Brain Res Rev 3:167-205. 